\title{
A VEINTE AÑOS DE LA REFORMA CONSTITUCIONAL DE 200I SOBRE DERECHOS Y CULTURA INDÍGENA EN MÉXICO: UN ANÁLISIS A LA LUZ DEL CONVENIO 169 DE LA OIT
}

\section{TWENTY YEARS AFTER THE 200I CONSTITUTIONAL REFORM ON INDIGENOUS RIGHTS AND CULTURE IN MEXICO: AN ANALYSIS IN THE LIGHT OF ILO CONVENTION 169}

\author{
Juan Manuel Belmonte Lozano \\ Universidad Pablo de Olavide, Sevilla, España \\ belmonte.lozano@gmail.com
}

Recibido: octubre de 2020

Aceptado: noviembre de 2020

\begin{abstract}
Palabras Clave: Constitución, derechos indígenas, derechos humanos, autodeterminación, propiedad colectiva.

Keywords: Constitution, indigenous rights, human rights, self-determination, collective ownership.
\end{abstract}

Resumen: El presente trabajo revisa la reforma de 2001 sobre derechos y cultura indígena emprendida en México por el Gobierno de Vicente Fox Quesada. A tales efectos se utiliza el Convenio 169 de la OIT como punto de vista comparativo para analizar los avances y retrocesos que implicaron las modificaciones constitucionales realizadas, y se distribuye el análisis en los cuatro ejes de mayor relevancia: el carácter pluricultural de la nación mexicana, la configuración del régimen de propiedad sobre la tierra, el derecho a la libre determinación y el reconocimiento del derecho consuetudinario indígena. La reforma fue limitada y condicionada por las deficiencias estructurales que impiden la efectiva acogida de las garantías indígenas en el Estado mexicano.

Abstract: This paper reviews the 2001 reform on indigenous rights and culture, undertaken in Mexico by the government of Vicente Fox Quesada. For this purpose, ILO Convention 169 is used as a comparative point of view to analyze the advances and setbacks of the constitutional modifications. The analysis is distributed in the four most relevant axes: the multicultural nature of the Mexican nation, the configuration of the land property regime, the right to selfdetermination, and the recognition of indigenous customary law. The reform was limited and conditioned by the structural deficiencies that impede the effective reception of indigenous guarantees in the Mexican State. 


\section{Introducción}

El día 14 de agosto de 2001 se aprobó la reforma constitucional que pretendía dar cumplimiento a lo pactado en los Acuerdos de San Andrés entre el Gobierno Federal y el Ejército Zapatista de Liberación Nacional (en adelante EZNL) ${ }^{1}$. En ellos se abogó por el refuerzo de una serie de derechos colectivos para las comunidades originarias del país, los cuales girarían en torno a dos reivindicaciones de base. La primera tenía que ver con la reintegración del carácter protegido de la propiedad

1. Los Acuerdos de San Andrés, Gobierno del Estado de Chiapas - Consejo Estatal para la Cultura y las Artes de Chiapas, México, 2003. Para un entendimiento de los compromisos acordados en San Andrés desde una perspectiva netamente jurídica y desde un análisis comparativo con la reforma de 2001 sobre derechos y cultura indígena, véanse, Cossío Díaz; J.R. “Análisis Jurídico de los Acuerdos de San Andrés Larráinzar", Este País: Tendencias y Opiniones, $\mathrm{n}^{\circ}$ 86, 1998, pp. 1-24; y Mata Miranda, A. R. "Pueblos indígenas en la construcción normativa. Consideraciones a partir de los acuerdos de San Andrés Larráinzar", Ciencia Jurídica, vol. 9, n 18, 2020, pp. 41-60.

Por otro lado, cabe reseñar que la importancia histórica del zapatismo y su actualidad en estos días no debe ceñirse al ámbito de los estudios estrictamente históricos. En sí mismo, el movimiento iniciado con la insurrección del EZLN supuso un antes y un después a la hora de entender la emergencia y mantenimiento de los movimientos sociales de resistencia. La razón de ello estriba en que dicho movimiento adoptó, por primera vez, las posibilidades ofrecidas por la red -internetcomo forma de tejer apoyos, sellar alianzas y promover la causa indígena más allá de las fronteras chiapanecas y mexicanas. Véanse, Schulz, M. S. "Nuevos medios de comunicación y movilización transnacional: el caso del Movimiento Zapatista", Perfiles latinoamericanos, vol. 22, no 44, 2014, pp. 171-194; y Rovira, G. Zapatistas sin fronteras: Las redes de solidaridad con Chiapas y el altermundismo, Ediciones Era, Mexico, 2009. social mexicana -ejidos y comunidades agrarias- retirado tras la reforma de 6 de enero de 1992 por el Gobierno de Carlos Salinas de Gortari². Dicho régimen de propiedad social se mantuvo desde la promulgación de la presente Constitución en 1917 hasta ese mismo año, y su objetivo no fue otro que el de distribuir las tierras y territorios que, hasta el período revolucionario mexicano -1910/1917-, habían quedado concentradas en pocas manos. Pues bien, dicha modificación no fue llevada a cabo por la reforma de 2001 y el artículo 27 restó igual; sin modificación alguna.

La segunda de las reivindicaciones de base reseñó la importancia de fundamentar las modificaciones constitucionales acordadas en San Andrés, en el que hasta ese momento era el único texto internacional referido a la protección de los derechos humanos de las minorías étnicas y tribales en el mundo: el Convenio número 169 de la Organización Internacional del Trabajo (en adelante OIT), aprobado en 1989 y ratificado por México el 5 de septiembre de $1990^{3}$. Para ello se antojaba

2. La retirada del carácter inembargable, imprescriptible e inalienable de los ejidos y comunidades agrarias resultó ser un "paso necesario" para satisfacer los puntos del Acuerdo de Libre Comercio con América del Norte (NAFTA, según sus siglas en inglés). Éste obligaba a establecer un único régimen de propiedad privado -además del público-, lo cual implicaba la derogación fáctica de toda forma comunal de tenencia. En sí misma, la reforma de 1992 fue el origen del conflicto. De hecho, no es una coincidencia que el levantamiento zapatista se produjese, precisamente, el día en que el NAFTA entró en vigor: el 1 de enero de 1994.

3. Convenio número 169 de la Organización Internacional del Trabajo sobre Pueblos Indígenas y Tribales en Países Independientes, adoptado por la Conferencia Internacional del Trabajo. En Gine- 
necesario que la reforma de 2001 sobre derechos y cultura indígena revisara la configuración del artículo 133 de la Constitución, el cual no recibió modificación alguna y siguió conservando la misma redacción tras la reforma objeto de la presente aportación:

Artículo 133 de la Constitución Política de los Estados Unidos Mexicanos: esta Constitución, las leyes del Congreso de la Unión que emanen de ella y todos los tratados que estén de acuerdo con la misma, celebrados y que se celebren por el presidente de la República, con aprobación del Senado, serán Ley Suprema de toda la Unión. Los jueces de cada entidad federativa se arreglarán a dicha Constitución, leyes y tratados, a pesar de las disposiciones en contrario que pueda haber en las Constituciones o leyes de las entidades federativas.

De dicho precepto se infería que los tratados firmados y ratificados por México tendrían que estar "de acuerdo" con la Constitución, por lo que el Convenio n 169 de la OIT quedaría subordinado a la misma4.

bra, Suiza, el 27 de junio de 1989, Diario Oficial de la Federación, 25 de septiembre de 1990.

El nacimiento del Convenio $n^{\circ} 169$ de la OIT estuvo marcado por la emergencia de los llamados derechos humanos de tercera generación. Esto es, aquellos derechos exclusivos de las minorías culturales y étnicas del mundo.

4. Esta cuestión fue advertida en algunos trabajos. Véase, Carbonell, M. "Constitución y derechos indígenas: introducción a la reforma del 14 de agosto de 2001", en M. Carbonell, (coord.) Comentarios a la reforma constitucional en materia indigena, Instituto de Investigaciones Jurídicas - UNAM, México, 2002, pp. 11-36. La problemática referida a la recepción del derecho internacional en materia indígena en el Estado mexicano fue analizada por Izquierdo Muciño, quien sugiere la dificultad en la recepción del derecho internacional según el citado artículo 133: Izquierdo Muciño, M.E. "El reconocimiento de los derechos de los pueblos indígenas en Méxi-
Con el incumplimiento de estos dos puntos de partida, difícilmente la reforma constitucional de 2001 sobre derechos y cultura indígena podía desarrollar los compromisos que el EZLN y el Gobierno Federal pactaron en San Andrés. Ésta, modificó los preceptos primero -al que se le añadió un segundo y tercer párrafos-y segundo -reformado íntegramente-. Asimismo, se derogó el primer párrafo del artículo cuarto, y se le añadió un sexto párrafo al decimoctavo y un último a la fracción tercera del artículo 115.

El presente trabajo trata de abordar la polémica reforma -a veinte años de su promulgación- teniendo como punto de vista comparativo el análisis del Convenio y cuatro epígrafes definidos: La nación indivisible, pluriculturalidad e identidad de lo indígena; ¿Derecho a la Tierra? Sustentabilidad y participación en los planes de desarrollo; Derecho a la libre determinación y autonomía: responsabilidad de las entidades federadas; y, finalmente, Justicia y sistemas normativos: derecho consuetudinario indígena y acceso a la jurisdicción del Estado.

co", Cuadernos Constitucionales de la Cátedra Fadrique Furió Ceriol, no 50, 2005, pp. 109-124. El artículo 133 sufrió una última modificación el 29 de enero de 2016, en la que se suprimió la última parte de su redacción: "Los jueces de cada entidad federativa se arreglarán a dicha Constitución, leyes y tratados, a pesar de las disposiciones en contrario que pueda haber en las Constituciones o leyes de las entidades federativas". Dicha alocución consagraba una mayor amplitud de miras a los jueces de cada entidad federativa, quienes debían arreglarse, no solo a la Constitución y las leyes, sino también a los tratados. Con esta reforma se reafirmó, por tanto, la preeminencia de la Constitución en la jerarquía de normas, relegando la aplicación de la normativa internacional a un segundo plano. 


\section{La nación indivisible, pluriculturalidad e identidad de lo indígena}

El artículo 2 de la reforma de 2001, en su primer párrafo, decía: "la nación mexicana es una e indivisible" 5 . Cultura y Derechos indígenas -objeto de las modificaciones que la acompañaron-, quedaron por ello sometidas de inicio a una Constitución que en el momento de su fundación no contempló a los pueblos originarios como sujeto de derechos colectivos legítimos. Esa alocución, "una e indivisible", llevó a algunos autores a criticar el talante dictatorial de dicho párrafo primero. Es el caso de Carbonell ${ }^{6}$, quien alegó que dicha expresión trasladaba a los siglos de opresión sufridos por los pueblos indígenas. Opresión que nunca dejó de existir hasta bien entrada la segunda mitad del siglo XX, donde aparecerían los llamados derechos de tercera generación -o derechos culturales-.

El hecho de empezar así el artículo en cuestión parecía responder al temor infundado de una posible orientación secesionista del movimiento indigenista, ya que, en atención a lo estipulado en los Acuerdos de San Andrés, se apostaba por una nueva unidad nacional que no supondría separación alguna. Así, la precitada indivisibilidad de la nación mexicana daba al Estado la base de fuerza necesaria para un reconocimiento un poco más profundo: la composición pluricultural del Estado mexicano "sustentada originalmente en sus comunidades indígenas"; descendientes "de

5. El artículo 2 según la reforma de 2001 pasó a componerse de seis párrafos con dos apartados A y $\mathrm{B}$, el primero con ocho fracciones y el segundo con nueve, para terminar con un párrafo final.

6. Decreto de Reforma Constitucional, Diario Oficial de la Federación, 28 de enero de 1992. poblaciones que habitaban en el territorio actual del país al iniciarse la colonización" y quienes conservaron "sus propias instituciones sociales, económicas, culturales y políticas, o parte de ellas".

Por tanto, la reforma de 2001 reforzaba la indivisibilidad de la nación mexicana -excluyendo toda posible plurinacionalidad o movimiento secesionista-, al tiempo que, como contrapunto, aceptaba el carácter pluriétnico y pluricultural de la misma. No se dio pie a un verdadero avance, puesto que se omitió la preexistencia de las comunidades indígenas mexicanas -anterior al establecimiento de las fronteras estatales- para considerarlas tan solo "descendientes". Es decir, no se recogió la redacción completa del que hasta entonces era el primero de los textos internacionales en materia de derechos humanos para las minorías étnicas y tribales del mundo -el Convenio 169 de la OIT-, en cuyo artículo primero -apartado b- ya se decía:

Artículo 1. Apartado b) del Convenio no 169 OIT: b) a los pueblos en países independientes, considerados indígenas por el hecho de descender de poblaciones que habitaban en el país o en una región geográfica a la que pertenece el país en la época de la conquista o la colonización o del establecimiento de las actuales fronteras estatales y que, cualquiera que sea su situación jurídica, conserven todas sus propias instituciones sociales, económicas, culturales y políticas, o parte de ellas.

Mientras en el Convenio se reafirmaba la existencia previa de las comunidades y pueblos indígenas al "establecimiento de las fronteras estatales", en la reforma de 2001, no. Así las cosas, cabe una primera reflexión: si las comunidades y pueblos indígenas no existían previamente a la formulación del Estado mexicano ¿de qué pacto social habrían participado? 
Si seguimos las interpretaciones clásicas del pacto social -las de Hobbes, Locke y Rousseau-, todas ellas definen un estado o condición conflictiva -de base- en el hombre, que les impele a crear una sociedad regida por una autoridad o gobierno, cuyas funciones son las de mantener el orden y dar cabida a todas las voluntades. Ahora bien, partiendo de que el origen del Estado mexicano se encuentra en la conquista y colonización, ese pacto social excluía de inicio la realidad indígena del país, ya que, como advirtió en su día Luís Villoro, en los planes de independencia se buscaba "establecer la unión de todas las clases sociales", obviándose la igualdad entre particularidades de tipo cultural -esto es, entre indígenas y no indígenas ${ }^{7}-$.

7. Una síntesis de las diferencias y similitudes en las teorías clásicas del pacto social (Locke, Rousseau, y Hobbes), es el realizado por: Cuéllar, O. "Pacto social y cuerpo político en la teoría política clásica", Argumentos, estudios críticos de la sociedad, $\mathrm{n}^{\circ} 20,1994$, pp. 85-99. Por otra parte, para un análisis de los discursos y planes que dieron origen a las ideas fundadoras del proceso de independencia, véase Villoro, L. La Revolución de Independencia, El Colegio de México, México, 2019. Esta es la tercera edición del original publicado por dicho autor en 1953.

La problemática de la exclusión-inclusión del indígena en el pacto social fundador del Estado mexicano, ha sido también analizada desde el punto de vista de las teorías de la nación. A este respecto, podemos destacar el siguiente trabajo: Ferrer Muñoz, M. y Bono López, M. Pueblos indígenas y Estado nacional en México en el siglo XX, Instituto de Investigaciones Jurídicas de la UNAM, México, 1998. En dicha monografía se analiza el rol histórico de los pueblos y comunidades indígenas en el ideario emancipador del Estado mexicano. Asimismo, conviene traer a colación un trabajo más reciente, pero más enfocado en la idea de nación desde la perspectiva del acceso al hábitat y al ejercicio del derecho a una tierra protegida: Martínez Coria, R. y Haro Encinas, J. A. "Derechos territoriales y pueblos
Por su parte, el párrafo tercero del artículo 2 según quedó reformado en 2001, expresó que la conciencia de la identidad indígena debía ser criterio fundamental para determinar a quiénes se aplicaban las disposiciones sobre los pueblos indígenas. La utilización de la expresión "quienes" daba a entender que la aplicabilidad de la normativa indígena -basada en el reconocimiento de derechos subjetivos colectivos- nunca iría más allá de la individualidad de la persona. Este hecho es importante, por cuanto el indígena es tal, en la medida de su pertenencia a una comunidad o pueblo - minoría étnica o tribal- que es sujeto mismo de derechos ${ }^{8}$.

indígenas en México: Una lucha por la soberanía y la nación", Revista pueblos y fronteras digital, vol. $10, n^{\circ} 19,2015$, pp. 228-256.

8. La evolución de la normativa internacional en materia de protección de derechos humanos ha evolucionado para incluir, no solo al individuo como sujeto de derechos, sino además al grupo o colectivo de personas cuyas singularidades culturales e históricas, les hacen susceptibles de ser considerado sujeto de derechos subjetivos colectivos. Cabe destacar a este respecto, que la venida de los derechos subjetivos colectivos fue teorizada por Karel Vasak, quien dividió dicha evolución en tres generaciones: la primera, referida a la eclosión de los movimientos revolucionarios franceses de finales del siglo XVIII; la segunda a la promulgación de la Declaración Universal de los Derechos Humanos de 1948 y, finalmente, la tercera, al desarrollo y evolución de la normativa internacional centrada en los derechos fundamentales de los pueblos y, más concretamente para el caso latinoamericano, los derechos de las comunidades y pueblos indígenas. Véanse, Vasak, K. Les Droits de l'Homme à l'aube du XXIème siècle, Bruylant, Bélgica, 1999; y Alcalde Parejo, S. El derecho de libre determinación de los pueblos. Un derecho humano de tercera generación en el nuevo constitucionalismo latinoamericano (Tesis Doctoral), UNED Universidad Nacional de Educación a Distancia, Madrid, 2018. 
Es más, el artículo 1.2 del propio Convenio especificaba que "la conciencia de su identidad indígena o tribal" debía "considerarse un criterio fundamental para determinar 'los grupos' indígenas".

En suma, la reforma de 2001 sobre derechos y cultura indígena acogió la pluriculturalidad de la sociedad mexicana. Sin embargo, reafirmó al mismo tiempo la indivisibilidad de una nación que excluyó en su origen las cosmovisiones originarias prehispánicas, y eludió el reconocimiento del carácter previo de las comunidades indígenas -sujeto de derechos subjetivos colectivos- al establecimiento de las fronteras del Estado tal y como sugería el propio Convenio 169 de la OIT.

En línea con lo anterior, la reforma partió de la consideración de un "indígena" -individualmente considerado-; no de un "pueblo indígena" sujeto de los derechos colectivos legítimos internacionalmente reconocidos y convalidados por el propio Estado mexicano. Estos dos puntos, no serían sino el hándicap estructural de toda una serie de modificaciones que,

9. Es conveniente precisar que la autoidentificación del indígena no fue una originalidad de la reforma, sino un avance impulsado por el progresivo reconocimiento de los derechos indígenas en la esfera internacional -incluyendo el propio Convenio 169 de la OIT-. No en vano, desde la década de los noventa, se fue introduciendo el criterio de autoadscripción en la identificación censal de personas indígenas en varios Estados latinoamericanos, lo que ha dado lugar a un "aumento" porcentual del tamaño de población indígena por país. Esto ha desembocado en la existencia del llamado "indígena urbano". Véanse, Schkolnik, S. y Del Popolo Oyarce, F. “, Notas de población, vol. 31, $\mathrm{n}^{\mathrm{O}} 79$, 2005, pp. 101-320; y también Herrera Amaya, M.E. "Comunidades indígenas urbanas: disputas y negociación por el reconocimiento", Revista Andamios, vol. 15, $\mathrm{n}^{\circ}$ 36, 2018, pp. 113-134. pretendiendo supuestamente el reconocimiento de garantías constitucionales a las comunidades indígenas mexicanas, no llegarían a ser más que una amalgama de contradicciones y demagogia palabrera.

\section{3. ¿Derecho a la tierra? Sustentabilidad y participación en los planes de desarrollo}

Como se ha visto, la reforma en cuestión acogió la pluriculturalidad de la sociedad mexicana, al tiempo que reafirmaba la indivisibilidad de una nación que excluyó la realidad indígena del país desde el origen. Así, con el objeto de salvar esta contradicción y comprender el alcance y grado de integración de las comunidades originarias tras las modificaciones constitucionales de 2001, hemos de hacer hincapié en el elemento distintivo básico de las culturas indígenas mexicanas -y amerindias en general-: el acceso al territorio; al hábitat. Lo han dicho desde hace décadas antropólogos e historiadores: el reconocimiento de una tierra protegida -inalienable, imprescriptible e inembargable- es el punto de partida para el desarrollo de los pueblos originarios y, por tanto, de sus derechos ${ }^{10}$.

10. A la vista de la literatura antropológica existente, se sabe del ineludible vínculo entre la identidad indígena y la "pertenencia" a un espacio territorial de la que es del todo inseparable. Dentro de estos estudios para podemos destacar el siguiente: Barabas, A. "El pensamiento sobre el territorio en las culturas indígenas de México", AVÀ Revista de Antropología (en línea), $\mathrm{n}^{\circ}$ 17, 2010, $\mathrm{n}^{\mathrm{o}} 17$, pp. $s / n$.

En lo relacionado al caso mexicano, la identidad original de las comunidades indígenas viene relacionada con la institución del Calpulli -forma 
El propio Convenio 169 de la OIT tuvo en cuenta lo anterior y enarboló un derecho a la tierra exclusivo para las minorías étnicas y tribales del mundo. De hecho, incluso en los propios Acuerdos de San Andrés se estableció el compromiso de retomar el carácter protegido de la propiedad social mexicana, retirado tras la reforma de 6 de enero de 1992 por el gobierno de Carlos Salinas de Gortari. Dicho régimen de propiedad-contemplado en el precepto 27 desde la promulgación de la Constitución en 1917- comprendía dos formas de tenencia colectiva: el ejido y las comunidades agrarias. La reforma de 2001 debía reinstaurar el carácter protegido de ambas figuras de propiedad modificando el precepto en cuestión, para volver a la situación original ${ }^{11}$. Como veremos, dicho

prehispánica de estructura socio-comunitaria, a partir de la cual evolucionó la propiedad social mexicana hasta nuestros días-. Véanse, Redfield, R. "El Calpulli-barrio en un pueblo mexicano actual", Nueva Antropología. Revista de Ciencias Sociales, 1982, pp-85-98; y Rodríguez Flores, C. E. "Suelo ejidal en México. Un acercamiento al origen y destino del suelo ejidal en México", Cuadernos de Investigación Urbanistica, $\mathrm{n}^{\circ} 57$, 2008, pp. 5-77.

11. Esa reivindicación, llamaba a una reinstauración de la propiedad social mexicana. Ésta vino establecida en el artículo 27 de a Constitución y, a pesar de sufrir diecinueve modificaciones desde 1917 a 1992, mantuvo el carácter inembargable, imprescriptible e inalienable con el que fue concebida desde el origen. En torno a los Acuerdos de San Andrés y la reivindicación de, entre otros, el derecho a una tierra protegida como pilar básico de las reivindicaciones indigenistas, puede consultarse, Gómez, M. "Los Acuerdos de San Andrés Sakamch'en: entre la razón de Estado y la razón de Pueblo", el Cotidiano, n 196, 2016, pp. 53-64.

Por otra parte, con respecto a la evolución histórica de dicho régimen de propiedad social, éste ha sido estudiado con gran minuciosidad por Chávez Padrón, M. Derecho Agrario Mexicano, compromiso -firmado por el Gobierno Federal en los Acuerdos- nunca tuvo lugar.

Si nos vamos al Convenio, éste establece la definición de "tierra" y el derecho de acceso al hábitat ancestral en su artículo 13 y, subsiguientemente, en el 14 y en el 15:

Artículo 13 del Convenio no 169 de la OIT: La utilización del término tierras en los artículos 15 y 16 deberá incluir el concepto de territorios, lo que cubre la totalidad del hábitat de las regiones que los pueblos interesados ocupan o utilizan de alguna otra manera.

Se elaboró un concepto de tierra en el que no hay demarcación geográfica que defina la pertenencia, sino que dicha demarcación vendría determinada por el uso y ocupación de ésta. Por tanto, el Convenio entiende la tierra como un espacio para el desarrollo de las prácticas culturales singulares que identifican al pueblo o comunidad. Es decir, no existen fronteras administrativas -ni territoriales- en esta definición, por lo que los límites de las tierras indígenas los marcan aquellas extensiones indeterminadas en las que se encuentren asentados y desarrollen sus prácticas culturales en comunidad ${ }^{12}$. En

Porrúa, México, 2001; donde se analizan desde un enfoque estrictamente jurídico, las formas de tenencia y propiedad, desde la etapa prehispánica hasta nuestros días.

12. Este entendimiento de la tierra en la normativa internacional ha dado lugar a una interpretación amplia del derecho indígena a la tierra; cuestión que ha venido siendo reflejada en estudios recientes. Véase, por ejemplo, Monsalve Suárez, S. "Derecho a la tierra y derechos humanos", $E l$ otro derecho, vol. 32, 2004, pp. 41-57; y Gilbert, J. "Derecho a la tierra como derecho humano: argumentos a favor de un derecho específico a la Tierra", Sur Revista Internacional de Derechos Humanos, vol. 18, n 10, 2013, pp. 123-145.

Para entender de manera comparativa la evolución del derecho indígena a la tierra en el ámbito regional, podemos recurrir a la investigación de 
otras palabras, "cultura" y "comunidad de personas" son las líneas que demarcan las fronteras de la comunidad o pueblo que se trate.

Con respecto al derecho a una tierra inembargable e imprescriptible, en el artículo 14.2 del Convenio se estableció: "los gobiernos deberán tomar las medidas que sean necesarias para determinar las tierras que los pueblos interesados ocupan tradicionalmente, y garantizar la protección efectiva de sus derechos de propiedad y posesión". Inmediatamente después, en el artículo 14.3 se dispuso: "deberán instituirse procedimientos adecuados en el marco del sistema jurídico nacional para solucionar las reivindicaciones de tierras formuladas por los pueblos interesados". Así, la reforma de 2001, al eludir la modificación del artículo 27 de la Constitución para reinstaurar el carácter protegido de la propiedad social mexicana retirado con la reforma de 1992, incumplió de origen, tanto con el propio Convenio como con los compromisos acordados en San Andrés.

Aun a pesar de ello, el Gobierno de Vicente Fox Quesada predispuso ciertas referencias indirectas a la problemática de la tierra en el apartado B del artículo 2 reformado, desgranando el llamado "Plan Nacional de Desarrollo". En dicho apartado se estableció que la Federación, los Estados y los municipios establecerían las instituciones y determinarían las políticas necesarias para garantizar la vigencia de los derechos indígenas y el desarrollo in-

Aylwin, quien no solo analiza las modificaciones en el régimen de propiedad colectiva en diversos Estados latinoamericanos, sino que ofrece datos estadísticos acerca de la dotación, devolución o cesión de tierras en los diferentes casos estudiados. Véase Aylwin, J. "El Derecho de los Pueblos Indígenas a la tierra y al Territorio", Harvard Human Rights Journal, vol. 33, 2001, pp. 1-35. tegral -ligado a la tenencia colectiva de la tierra- de sus pueblos y comunidades ${ }^{13}$.

Es más, si avanzamos en este apartado B del artículo 2 tal y como quedó tras la reforma de 2001, nos encontramos con una fracción, la IX, que establecía la obligación de "consultar a los pueblos indígenas en la elaboración del Plan Nacional de Desarrollo -así como estatales- y, 'en su caso', incorporar las recomendaciones y propuestas" que ellos mismos realizasen. Al introducir la expresión "en su caso", claramente se daba pie a una postura negativa por parte de las autoridades encargadas de desarrollar estas garantías, allí donde considerasen perjudicial para sus intereses, las exigencias, recomendaciones u opiniones de los representantes indígenas.

En lo que concierne a las fracciones quinta y sexta del apartado A del artículo 2 modificado en 2001, se concedió a las comunidades y pueblos indígenas la libre determinación y, en consecuencia, la autonomía para conservar y mejorar el hábitat "dentro de los términos establecidos por la Constitución". Pues bien, esos términos constitucionales remitían nuevamente a la misma cuestión: la propiedad privada y la no reinstauración del carácter inviolable de los ejidos y las comunida-

13. Los juristas han venido entendiendo este derecho, como un derecho sobre los recursos que son propios a los hábitats o regiones que los indígenas habitan. Asimismo, se da especial relevancia al principio de sustentabilidad del medioambiente como principio rector de la cosmovisión de estos pueblos. En esta línea, sustentabilidad medioambiental y acceso a los recursos dentro de una tierra inembargable, imprescriptible e inalienable, garantizaría, para los indígenas, el efectivo cumplimiento del derecho a la tierra como tal. Véase Gaona Pando, G. "El derecho a la tierra y protección del medio ambiente por los pueblos indígenas", Nueva antropología, vol. 26, $\mathrm{n}^{\mathrm{o}} 78$, 2013, pp. 141-161. 
des agrarias retirado tras la reforma de $1992^{14}$. No se les podía garantizar eficazmente el hábitat-y, por ende, la pervivencia- a las poblaciones indígenas, si existía ya de base un sistema de propiedad sobre el suelo que exponía en todo momento las tierras a la especulación. De hecho, la reforma de 2001 intensificó el proceso de desaparición de la propiedad social indígena, contraponiéndose el desarrollo normativo del Convenio en el articulado constitucional:

14. En lo que respecta a la evolución del artículo 27 de la Constitución mexicana, y las 19 modificaciones acometidas al mismo desde 1917 a 1992, véase: Belmonte Lozano, J.M. El derecho indígena a la tierra en México, Editorial REUS, Madrid, 2016. En este trabajo se explican, igualmente, los vínculos entre la organización político-administrativa de las comunidades indígenas mexicas y las formas de propiedad comunal originarias de tales poblaciones -esto es, prehispánicas-. En ella, se estudia la simbiosis que siguió la tenencia colectiva de la tierra en México, desde el Calpulli como forma de propiedad precolonial, hasta el diseño de las comunidades agrarias y los ejidos en el siglo $\mathrm{XX}$. Asimismo, se incluye un breve avance a los puntos candentes de la reforma de 2001 objeto del presente trabajo (páginas 191-198).

Dentro de toda esta problemática; a saber, la de la importancia e impacto de la retirada del carácter protegido de ejidos y comunidades agrarias tras la reforma de 6 de enero de 1992, cobra especial relevancia la labor del Programa de Certificación de Derechos Ejidales y Titulación de Solares (PROCEDE), sobre cuyas funciones se han centrado organismos internacionales criticándole el espíritu neoliberal de sus funciones, al promover la compraventa de los solares ocupados por comunidades y pueblos indígenas mexicanos. Cabe destacar que las funciones del PROCEDE se sustentan, en último término, en la configuración del régimen de tenencia según éste se establece en el artículo 27 de la Constitución mexicana. Para saber más a este respecto, véase Barnes, G. "The evolution and resilience of community-based land tenure in rural Mexico", Land Use Policy, vol. 26, nº 2, 2009, pp. 393-400.
Artículo 2. Apartado A. Fracción V (según la reforma de 2001): (Esta Constitución reconoce y garantiza el derecho de los pueblos y las comunidades indígenas a la libre determinación y, en consecuencia, a la autonomía para conservar y mejorar el hábitat y preservar la integridad de sus tierras en los términos establecidos en esta Constitución): V. Acceder, con respeto a las formas y modalidades de propiedad y tenencia de la tierra establecidas en esta Constitución (...) y disfrute preferente de los recursos naturales de los lugares que habitan y ocupan las comunidades, salvo aquéllos que corresponden a las áreas estratégicas, en términos de esta Constitución.

Como puede verse, se le otorgó a los pueblos y comunidades indígenas el uso preferente de la tierra como derecho, pero volviéndose a limitar su ejercicio, esta vez, cuando los hábitats ocupados respondiesen a "intereses estratégicos" según dictase la Constitución ${ }^{15}$. Para remisión comparativa de lo mencionado en el párrafo anterior, nos trasladamos al artículo 7.4 del Convenio, el cual no dejaba lugar a objeciones: "los gobiernos deberán tomar medidas en cooperación con los

15. En sí misma, la reforma consagró el espíritu neoliberal de las modificaciones constitucionales acometidas al artículo 27 en la reforma que el gobierno de Carlos Salinas de Gortari promulgó el 6 de enero de 1992. Así, a pesar de habérseles reconocido la "preexistencia" de los indígenas, a la formación del Estado mexicano, el carácter capitalista de las reformas de 1992 y 2001 rehuyeron de afianzar el derecho de sus comunidades y pueblos a una tierra inembargable, imprescriptible e inalienable. Prueba de esta reflexión podemos encontrarla en el siguiente aporte: López Bárcenas, F. "Pueblos indígenas y megaproyectos en México: las nuevas rutas del despojo", en A. Ávila Romero (coord.) Patrimonio biocultural, saberes y derechos de los pueblos originarios Patrimonio biocultural, Universidad Intercultural de Chiapas, México, 2011, pp.123-140. 
pueblos interesados para proteger y preservar el medio ambiente de los territorios que habitan". De hecho, el artículo $7.1 \mathrm{del}$ mismo es más tajante aún, pues obligaba ya a las autoridades ejecutivas a respetar determinados derechos e instrumentos de participación de los pueblos indígenas, lo cual se antojaba complicado según la reforma, ya que ésta, no solo supuso la confirmación de la pérdida del carácter protegido de la propiedad social mexicana, sino la remisión de toda voluntad comunitaria indígena a la conformidad con los intereses estratégicos dictados por el Gobierno Federal o aquéllos de las entidades federadas y/o municipales.

En conclusión, el Plan Nacional de Desarrollo esbozado en la reforma de 2001, no solo no cumplió con los Acuerdos de San Andrés al no reinstaurarse el carácter inviolable de la propiedad social mexicana en su precepto 27 , sino que además evadió por completo el Convenio en lo relativo al derecho subjetivo colectivo a una tierra inembargable, imprescriptible e inalianable. Por lo mismo, se limitó ostensiblemente la eficacia del derecho a ser consultados o a participar en los Planes de Desarrollo o proyectos que tuvieren lugar sobre sus hábitats, al quedar ambos condicionados a no contradecir los intereses estratégicos de las autoridades gubernamentales.

\section{Derecho a la libre determinación y autonomía: responsabilidad de las entidades federadas}

Tres eran -y siguen siendo- los problemas estructurales asociados al reconocimiento de la libre determinación y la autonomía política de los pueblos indígenas en Mé- xico: el marco legal habilitante, la estructura federal del Estado y, dentro de ella, la garantía del carácter inviolable en el acceso al territorio como hábitat natural para el desarrollo libre y autónomo de sus culturas $^{16}$.

De forma constante en toda la reforma, la libre determinación quedó limitada por la "soberanía nacional", por la "unidad nacional", por "una ley reglamentaria posterior" o, como es el acaso ahora, por un "marco constitucional" o "marco legal habilitante". Por ejemplo, en la fracción III del apartado A del artículo 2 se estableció que la libre determinación quedaría limitada por un marco constitucional de autonomía que asegurase la unidad nacional, para después reconocer y garantizar el derecho a la libre determinación y autonomía para elegir de acuerdo con sus normas, procedimientos y tradiciones, a sus autoridades y representantes. Así también, en la fracción I del apartado A del artículo 2 se predispuso que las comunidades y pueblos indígenas tenían "el derecho a la libre determinación 'para' decidir sus formas internas de convivencia y organización social, económica, política y cultural".

En todo el artículo 2, tal y como quedó redactado tras las modificaciones comentadas, las prácticas y costumbres internas indígenas quedaron sometidas a la previa configuración de un derecho a la libre determinación "para" ser reconocidas y

16. Con relación a la problemática de la autonomía indígena como forma de resolución de los conflictos étnicos en México tras el alzamiento zapatista de 1994 y la posterior firma de los Acuerdos de San Andrés, véase Gutiérrez Chong, N. "La autonomía y la resolución de conflictos étnicos: Una perspectiva de los Acuerdos de San Andrés Larráinzar", Nueva antropología, vol. 19, no 63, 2003, pp. 11-39. 
legalmente contempladas, mientras que en el artículo 8 del Convenio -relativo a la organización interna de las comunidades y pueblos indígenas- se reseñaba la necesidad de tener en cuenta sus costumbres y su derecho consuetudinario como fundamento configurador de ese derecho a la libre determinación ${ }^{17}$.

17. En la reforma en cuestión no se explicitó la posesión comunitario-colectiva de tierras protegidas como base de las prácticas consuetudinarias indígenas, por lo que las garantías supuestamente cubiertas por la modificación constitucional de 2001 , restaron ambiguas y, por consiguiente, restrictivas. La importancia del vínculo entre el derecho consuetudinario mexica -prehispánico- y la existencia de comunidades singularizadas y establecidas en espacios territoriales definidos, ha sido trabajado tanto desde el punto de vista histórico-jurídico, como antropológico. Con relación al primero, se ha de reseñar la aportación llevada a cabo por Brokmann Haro, C. La flecha dorada: pluralismo y derechos humanos en los sistemas jurídicos de Mesoamérica, Comisión Nacional de los Derechos Humanos, México, 2018. Dicho autor insiste en la necesidad de extender la interpretación y estudio de los derechos humanos de las minorías étnicas, al ámbito antropológico y desde una perspectiva histórico-evolutiva: Brokmann Haro, C. "Antropología y derechos humanos", Revista del Centro Nacional de Derechos Humanos, 1993, pp. 57-63. En un aporte ulterior, refiere que "los derechos humanos son un medio para lograr la dignidad de las personas, pero deben ser estudiados a la luz de la antropología para su verdadera efectividad, ya que las diferencias en el debate cultural entorpecen también la colaboración entre Estados para su tutela". Véase, Brokmann Haro, C. "La Doctrina del Margen de Apreciación como instrumento de la protección de los derechos humanos", Centro Nacional de Derechos Humanos-CNDH-, Año 3, no 8, México, 2008, pp. 57-87

Más allá de lo anterior, multitud de antropólogos han venido reflejando la importancia del acceso al territorio como pilar base de la estructuración de las sociedades indígenas prehispánicas, lo cual nos llevaría a comprender el origen y la posición de preeminencia del derecho indígena a
En línea con la interpretación anterior, en el Convenio 169 de la OIT encontramos la participación y representación política en los artículos 6 y 8 . En el apartado primero del artículo 8 se dispuso que "al aplicar la legislación nacional a los pueblos interesados" habrían de tenerse en cuenta "sus costumbres o su derecho consuetudinario". De esta forma, el Convenio daba ya validez a la costumbre asentándola como la base para el ejercicio de la autonomía comunitaria. Aun más, en el artículo 8.2 del Convenio se indicaba que dichos pueblos debían tener "el derecho a 'conservar' sus costumbres e instituciones propias". La diferencia con la reforma de 2001 en este sentido radicó nuevamente en que el Convenio, al utilizar el término "conservar", daba por sentada la existencia de sus costumbres y formas propias de representación y organización política. En cambio, en la reforma de 2001 estas formas de participación y representación políticas consuetudinarias solo podían reconocerse -y definirse- una vez se les concediese un marco legal de autonomía a las comunidades indígenas.

En suma, mientras que en el Convenio se reconocían las formas propias de organización, participación y representación política como el reflejo de la libre determinación y autonomía, en la reforma de 2001, el libre ejercicio de esas formas propias de organización, participación y representación política quedaba supeditado a un marco legal que las reconociese y legalizase. Por tanto, su regulación no dependería de las comunidades indíge-

una tierra inviolable con respecto al resto de garantías que los pueblos indígenas actuales vienen reclamando. Véase, Viveiros de Castro, E. "Perspectivismo y multiculturalismo en la América indígena", O que nos faz pensar, vol. 14, $\mathrm{n}^{\circ} 18$, 2004, pp. 225-254. 
nas, puesto que para que éstas pudiesen participar, necesitaban estar previamente habilitadas por un marco de autonomía y de libre determinación no exclusivamente definido por ellas.

En otro orden de ideas, la autonomía y libre determinación implicaban -e implican- para el caso mexicano, la necesidad de auto-demarcar el propio territorio y, desde aquí, replantear una nueva relación con las instituciones estatales. Dicha problemática se antojaba ya en 2001 bastante complicada, siendo la estructura federal uno de los obstáculos de base al reconocimiento efectivo de la libre determinación y autonomía ${ }^{18}$. Las razones de ello se centran en un hecho a todas luces palmario: la existencia de pueblos indígenas sometidos a la jurisdicción de dos o más entidades federadas y/o municipios distintos.

Esta cuestión no fue contemplada de manera específica en el Convenio 169 de la OIT, dado que se trata de un instrumento jurídico de carácter general y, por ende, se remite al desarrollo normativo por parte de los Estados. No obstante, en los Acuerdos de San Andrés se acordó una re-demarcación territorial de los distritos uninominales y circunscripciones electo-

18. Wilhelmi subrayó que la autonomía política según los movimientos indígenas mexicanos, implicaba la elección de autoridades con potestades para legislar y administrar los asuntos internos, lo que nos lleva a pensar que, en efecto, no se precisaba de la creación de un marco para el ejercicio de la libre determinación política -tal y como se sugería en la reforma- sino que ese marco ya venía definido por el reconocimiento de la singularidad cultural y de las costumbres propias de las comunidades indígenas. Wilhelmi, M. A. "La libre determinación y la autonomía de los pueblos indígenas: El caso de México", Boletín mexicano de derecho comparado, vol. $42, \mathrm{n}^{\circ}$ 124, 2009, pp. 13-38. rales plurinominales, así como una remunicipalización que permitiese la unión de pueblos y comunidades indígenas pertenecientes a municipios diferentes. Dicha re-demarcación y remunicipalización permitiría una mejor representación y participación política de las comunidades y pueblos indígenas. A pesar de ello, en la reforma de 2001, aunque se hicieron modificaciones al respecto en el artículo 115 de la Constitución Federal, se acabó obviando la remunicipalización pactada en los Acuerdos y se enterró de golpe todo atisbo de apertura en esta cuestión. No en vano, el párrafo agregado a la fracción III de dicho artículo estipuló lo siguiente: "las comunidades indígenas, dentro del ámbito municipal, podrán coordinarse y asociarse en los términos y para los efectos que prevenga esta ley". Quedó claro que resultaba imposible la remunicipalización si la asociación entre comunidades indígenas quedaba sujeta, como se dijo, al ámbito municipal preestablecido e incuestionable ${ }^{19}$.

Siguiendo con el problema que supone la estructura federal del Estado mexicano a la hora de reconocer la libre determina-

19. La cuestión de la re-demarcación territorial de los pueblos y comunidades indígenas es vital para entender el derecho indígena a la tierra, ya que al ser México un Estado federal, muchas de las comunidades y pueblos indígenas mexicanos dispersos por el territorio nacional comparten una lengua propia e iguales costumbres $\mathrm{y}$, sin embargo, se encuentran sometidos a jurisdicciones diferentes; esto es, a una o varias entidades federadas distintas. Esta cuestión ha sido advertida de manera constante por López Bárcenas, quien destacó el "yerro histórico" que supuso la conformación de un Estado mexicano que acabó heredando la estructura administrativo-territorial del periodo colonial sin tener en cuenta "las ubicaciones geográficas de los pueblos indígenas". Véase, López Bárcenas, F. "Los Acuerdos de San Andrés, proceso constituyente y reconstitución 
ción a las comunidades y pueblos indígenas, es preciso remitirnos a la fracción III del apartado A del artículo 2 tal y como quedó reformado en 2001, donde se estableció que, a los indígenas, en el seno de sus comunidades y/o pueblos, se les permitiría "elegir de acuerdo con sus normas, procedimientos y prácticas tradicionales a las autoridades o representantes para el ejercicio de sus formas propias de gobierno". Ahora bien, esto quedaba condicionado a "respetar el pacto federal y la soberanía de los Estados". ¿Qué "nueva relación" o pacto social -al que se comprometió el gobierno federal en los Acuerdos de San Andrés- se podía construir si, precisamente, las comunidades indígenas estaban sujetas al ya existente? ¿Cómo podía ejercerse el derecho a la autonomía, si ésta obligaba ya a cumplir el pacto federal y la estructura territorial que le dio origen? ¿De qué modo se habría podido ejercer el derecho a la libre determinación sin una re-demarcación territorial que permitiese la reintegración de pueblos indígenas sometidos a jurisdicciones federales $-\mathrm{y} / \mathrm{o}$ municipales- diferentes?

A tenor de tales obstáculos, la libre determinación dibujada por la reforma implicaba una libertad de autogobierno sencillamente imposible. Es más, con las

de los pueblos indígenas", El Cotidiano, no 196 , 2016, p. 87-94.

Además de lo anterior, y como se ha venido recalcando a lo largo del presente trabajo, el ejercicio del derecho a la libre determinación debe entenderse en relación con la garantía de acceso a una tierra o propiedad colectiva inviolable. Véase, Assies, W. "Los pueblos indígenas, la tierra, el territorio y la autonomía en tiempos de globalización", en S. Martí i Puig, (coord.) Pueblos indígenas y política en América Latina: el reconocimiento de sus derechos y el impacto de sus demandas, Fundació CIDOB, Barcelona, 2007, pp. 227-245. restricciones que la reforma planteaba, a las comunidades indígenas no se les dejaba más que un camino posible para ejercer su derecho a la libre determinación y autonomía: desgajarse del Estado y sus entidades federadas y municipales, para después unirse bajo nuevos términos. López Bárcenas lo explicaba bien al afirmar que "pocos efectos pudiera tener si algún indígena quisiera dividir la nación, porque difícilmente invocaría la protección de la Constitución Federal para hacerlo, ya que implicaría acogerse a ella para destruirla20".

Con todo, no queda sino argüir que la propia estructura federal inamovible del Estado hizo que la reforma de 2001 fuese en todo término restrictiva, e impedía el cumplimiento de los compromisos que el gobierno y el EZLN pactaron en los Acuerdos de San Andrés, con relación al ejercicio de los derechos de libre determinación y autonomía.

\section{Justicia y sistemas normativos: derecho consuetudinario indígena y acceso a la jurisdicción del Estado}

El objetivo de la reforma de 2001 sobre derechos y cultura indígena perseguía el reconocimiento de los derechos subjetivos colectivos que el Gobierno Federal y el

20. López Bárcenas, F. Legislación y derechos indígenas en México. MC editores, México, 2010. p. 53. El desarrollo de las competencias en materia de protección y desarrollo de los derechos indígenas fue delegada expresamente a las propias entidades federadas y listadas, de hecho, en las nueve fracciones del apartado B del artículo 2 reformado. 
EZLN acordaron en San Andrés. El marco de referencia para el cumplimiento de los compromisos de aquel pacto se centró especialmente en dos puntos. El primero de ellos abogaba por la efectiva aplicación del Convenio 169 de la OIT y el segundo por la reinstauración del carácter protegido de la propiedad social mexicana -de los ejidos y de las comunidades agrarias por igual-.

En torno a estos dos puntos habría de virar, tanto el reconocimiento de la plurinacionalidad o realidad indígena diferenciada del país, como la garantía de un acceso inviolable a un espacio o hábitat cuyos límites eran definidos por las particularidades culturales de cada comunidad o pueblo. Complementando ambos casos, la inclusión del derecho consuetudinario indígena debía servir como base para cerrar el círculo de las demandas indígenas: elegir sus propias instituciones jurídicas o políticas, sus propios representantes -conforme a sus pautas tradicionales-, utilizar sus lenguas y darles la oficialidad necesaria para ser juzgados en la misma, etcétera ${ }^{21}$.

Con la reforma de 2001 sobre derechos y cultura indígena, los derechos humanos de las minorías étnicas desarrollados en los preceptos constitucionales modificados fueron sometidos en todo momento a las garantías individuales. Por ello, el Convenio -que integra exclusivamente derechos de carácter colectivo-, no solo

21. El reconocimiento de la jurisdicción indígena supone la reafirmación del derecho a la libre determinación de sus comunidades o pueblos. Ambas garantías han de entenderse de manera conjunta e inseparables. Véase, Colaço, T. L. "El reconocimiento constitucional del derecho y la jurisdicción indígena como afirmación de la autodeterminación de los pueblos indígenas", Alegatos, vol. 28, no 87, 2017, pp. 241-258. no podía servir de base para la efectiva inclusión de las minorías étnicas y tribales en el Estado mexicano, sino que además resultaba ser del todo inefectivo ${ }^{22}$.

En orden con la reflexión comentada, si nos vamos al apartado primero del artículo 9 del Convenio, vemos lo siguiente:

Artículo 9.1 del Convenio $n^{\circ} 169$ de la OIT: En la medida en que ello sea compatible con el sistema jurídico nacional y con los derechos humanos internacionales reconocidos, deberán respetarse los métodos a los que los pueblos interesados recurren tradicionalmente para la represión de los delitos cometidos por sus miembros.

Como puede observarse, aunque el propio Convenio limitaba las normas consuetudinarias -colectivas y propias de los pueblos indígenas- a la compatibilidad con el sistema jurídico nacional, subrayaba el deber de respetar los derechos humanos, no mencionando nada acerca de "garantías individuales"; cosa que si ocurría en

22. Como se ha venido diciendo en el presente trabajo, el Convenio fue el primero de los instrumentos internacionales exclusivamente diseñado para la protección de los derechos de las minorías étnicas en el mundo. Dado su carácter general, la aplicabilidad y adecuación de éste al interior de los diferentes estados, obliga a un análisis particularizado de la realidad de cada país, ya que cada comunidad o pueblo indígena tiene, en sí mismo, normas culturales distintas. He aquí la labor de la antropología jurídica y su objetivo por documentar lo que Sierra Camacho llama "las formas contemporáneas del derecho indígena y su materialidad en el campo de la justicia". Dicha autora arguye que la labor de la antropología jurídica contribuye a "desestabilizar las nociones hegemónicas del derecho y a disputar su definición en los espacios mismos de la producción jurídica". Véase, Sierra Camacho, M.T. "Del derecho consuetudinario a la justiciabilidad de los derechos indígenas: el legado de Rodolfo Stavenhagen a la antropología jurídica", Desacatos, $\mathrm{n}^{\mathrm{o}} 57,2018$, pp.156-165. 
la fracción II del apartado A del artículo 2 reformado, donde se predispuso que la Constitución reconocía y garantizaba el derecho de los pueblos y comunidades indígenas a "aplicar sus propios sistemas normativos en la regulación y solución de sus conflictos internos", sujetándose a los principios generales de la Constitución y "respetando las garantías individuales y los derechos humanos". Ahora bien, ¿De qué manera podían reconocerse los derechos humanos de las minorías étnicas en México -de carácter colectivo- si éstos quedaban sometidos a las garantías individuales?

La aplicación de los propios sistemas normativos internos de los pueblos originarios para la resolución de sus conflictos de convivencia quedó sujeta a la Constitución y al respeto de las "garantías individuales". Así, la autonomía interna -basada en el libre ejercicio de las propias normas consuetudinarias comunitarias- quedó de inicio restringida. Por ejemplo, entre esas garantías se encontraba la del derecho a la propiedad y, si retomamos el artículo 27, el cual desprotegía los ejidos y las tierras comunales declarándolos transferibles, vemos cómo el ámbito de autonomía reconocido a las comunidades indígenas no servía para frenar la especulación sobre determinados terrenos llevada a cabo por personas o municipios, ya que tal derecho a la propiedad es una garantía individual $y$, en consecuencia, prevalecería sobre el colectivo indígena y sobre el desarrollo de sus normas tradicionales de organización socio-comunitaria.

Además, si bien el acceso pleno a la jurisdicción del Estado de las comunidades y pueblos indígenas quedaba garantizado por la reforma de 2001, se condicionaba el reconocimiento del derecho consuetudinario a la validación según dispusiese la ley. De hecho, en la fracción VIII del apar- tado segundo del artículo 2, se garantizaba el efectivo acceso a la jurisdicción del Estado para las comunidades indígenas del país, empero subsiguientemente se dijo: "se deberán tomar en cuenta sus costumbres y especificidades culturales respetando los preceptos de esta Constitución". Es decir, se "tendrían en cuenta sus costumbres y especificidades culturales" sin garantizarle a los pueblos y comunidades indígenas la posibilidad de introducirlas en el marco del derecho positivo a fin de reconocerles la reivindicación de poder resolver, según sus usos y costumbres, tanto los conflictos internos relativos a los distintos ámbitos de la vida social en la comunidad, como los conflictos de carácter intercultural entre indígenas y no indígenas ${ }^{23}$.

\section{Conclusiones}

La reforma de 2001 sobre derechos y cultura indígena incluyó el carácter pluricultural de la sociedad mexicana, reafirmando la indivisibilidad de una nación que excluyó el carácter singular y diferenciado de las cosmovisiones originarias indias.

23. A juicio de Aragón Andrade, la inclusión de los sistemas jurídicos indígenas en el artículo 2 fue un avance importante. No obstante - señalael texto constitucional resultaba tan limitante, que prácticamente condenaba el reconocimiento de las normas consuetudinarias indígenas a la mera resolución de conflictos menores. De hecho, las modificaciones realizadas con la reforma de 2001 sobre derechos y cultura indígena quedaron siempre restringidas `por la "sujeción", la "armonización", la "adecuación”, o la "validación" de los derechos colectivos indígenas, a la propia Constitución. Véase, Aragón Andrade, O. "Los sistemas jurídicos indígenas frente al derecho estatal en México: Una defensa del pluralismo jurídico", Boletín mexicano de derecho comparado, vol. 40, no 118, 2007, pp. 9-26. 
Una contradicción que fue reforzada al eludir el carácter previo de las comunidades indígenas al establecimiento de las fronteras del Estado tal y como si hacía el Convenio. De ahí que el reconocimiento de la realidad indígena del país, esbozado por la reforma en el artículo 2 de la carta magna mexicana, no alcanzase a ser más que humo para la confusión.

Más allá de lo anterior, la inclusión y reconocimiento de la realidad indígena debía tener en cuenta una nueva reforma al artículo 27 con el fin de reinstaurar el carácter protegido -inembargable, imprescriptible, e inalienable- de la propiedad social mexicana, retirado el 6 de enero de 1992. Y ello porque la tierra es, como han venido vislumbrando los antropólogos a este respecto, el elemento definitorio principal de la identidad indígena mexicana $-y$ amerindia en general-. La reforma de 2001 sobre derechos y cultura indígena no solo obvió por completo esta modificación, sino que no tomó ni como referencia al Convenio -que desgranaba ya esta garantía en sus artículos 13 y siguientes.

Por otro lado, aunque la reforma introdujo la prescripción de llevar a cabo planes nacionales de desarrollo integral para los pueblos originarios, las comunidades indígenas tendrían su derecho a participar y a ser consultadas en el diseño e implementación de éstos, pero siempre restringido a no contradecir los intereses estratégicos gubernamentales -federales, estatales o municipales-.

Con respecto a la autonomía y libre determinación, los Acuerdos de San Andrés hablaban de la reconstrucción del pacto social mediante la creación de normas que acotasen un nuevo marco jurídico en el seno de una nueva relación. No obs- tante, la mayoría de los ámbitos de libre determinación y autonomía reconocidos a que alegaron las modificaciones constitucionales de 2001 siempre encontraron la traba de someterse al pacto federal ya existente, por lo que ese intento de redefinición de las relaciones entre los pueblos indios de México y el Estado, por sí solo, quedó sin efecto.

Es más, la reforma de 2001 sobre derechos y cultura indígena proponía a la Constitución como garante de un nuevo marco para la libre determinación y autonomía, siempre y cuando éste se adecuase a: 1) la incuestionable propiedad privada -incompatible con el reconocimiento de los derechos subjetivos colectivos de las comunidades indígenas-, 2) la rigidez inalterable de su estructura federal y municipal y, 3) los irrebatibles planes estratégicos que dictasen las autoridades gubernamentales. Todos estos aspectos, contrarios a lo estipulado en el Convenio, impedían sentar las bases para el efectivo ejercicio del derecho a la libre determinación por parte de las comunidades indígenas mexicanas.

En lo que se refiere al reconocimiento del derecho consuetudinario indígena, la reforma de 2001 volvió a ser restrictiva con respecto al desarrollo normativo esbozado por el Convenio 169 de la OIT. Aunque éste último limitaba dicho reconocimiento a la compatibilidad con el ordenamiento jurídico nacional, reseñó el deber de garantizar los derechos humanos colectivos como pieza fundamental. De hecho, la reforma, al objeto de mantener la preminencia de las garantías de la persona por encima de los de la comunidad o pueblo, sometió la inclusión y desarrollo normativo del derecho consuetudinario indígena a las garantías individuales. 
La reforma en cuestión integró avances al desarrollar parte del articulado del Convenio 169 en la propia Constitución. Sin embargo, tal evolución estuvo seguida de una constante remisión al carácter preminente de la carta magna en la jerarquía normativa del ordenamiento jurídico mexicano. Así, partiendo de la no modificación del precepto 133 de la Constitución, el Convenio 169 no sirvió más que como mera referencia para el desarrollo de unos derechos colectivos indígenas limitados por el pacto constitucional ya existente -y excluyente para con la realidad originaria del país-, por un régimen de propiedad privado y especulativo, por una demarcación administrativo-territorial inamovible, por un autogobierno limitado, y por la sumisión de los planes de desarrollo a los intereses estratégicos de las autoridades gubernamentales. 
